\title{
Factor Structure of the Coaching Behavior Questionnaire and Its Relationship to Athlete Variables
}

Jean M. Williams

University of Arizona

Gerald J. Jerome

University of Illinois at Urbana-Champaign

Laura J. Kenow

Linfield College

Tracie Rogers

Arizona State University

Tessa A. Sartain

University of Arizona

See next page for additional authors

Follow this and additional works at: https://digitalcommons.linfield.edu/hhpafac_pubs

Part of the Sports Sciences Commons

This Published Version is protected by copyright and/or related rights. It is brought to you for free via open access, courtesy of DigitalCommons@Linfield, with permission from the rights-holder(s). Your use of this Published Version must comply with the Terms of Use for material posted in DigitalCommons@Linfield, or with other stated terms (such as a Creative Commons license) indicated in the record and/or on the work itself. For more information, or if you have questions about permitted uses, please contact digitalcommons@linfield.edu. 


\section{Authors}

Jean M. Williams, Gerald J. Jerome, Laura J. Kenow, Tracie Rogers, Tessa A. Sartain, and Greg Darland

\section{DigitalCommons@Linfield Citation}

Williams, Jean M.; Jerome, Gerald J.; Kenow, Laura J.; Rogers, Tracie; Sartain, Tessa A.; and Darland, Greg, "Factor Structure of the Coaching Behavior Questionnaire and Its Relationship to Athlete Variables" (2003). Faculty Publications. Published Version. Submission 3.

https://digitalcommons.linfield.edu/hhpafac_pubs/3 


\title{
Factor Structure of the Coaching Behavior Questionnaire and Its Relationship to Athlete Variables
}

\author{
Jean M. Williams \\ University of Arizona
}

Laura J. Kenow

Linfield College

\author{
Gerald J. Jerome \\ University of Illinois
}

\author{
Tracie Rogers \\ Arizona State University
}

\section{Tessa A. Sartain and Greg Darland University of Arizona}

\begin{abstract}
Little research exists to identify optimal coaching behaviors and factors that influence the effectiveness of particular behaviors. The present study tested 484 athletes in order to determine sub-scales on the Coaching Behavior Questionnaire (CBQ). The CBQ measures athletes' perceptions of coaching behaviors and evaluates their effectiveness in helping athletes play better and maintain optimal mental states and focus. A confirmatory factor analysis (CFA) supported the two-factor model (negative activation, supportiveness/emotional composure) derived from an exploratory factor analysis (EFA). Correlational analyses indicated that athletes with higher anxiety and lower self-confidence and compatibility with the coach were more likely to negatively evaluate coaching behaviors. The results support and expand on Smoll and Smith's (1989) model of leadership behaviors in sport.
\end{abstract}

The coach is the most important person in determining the quality and success of an athlete's sport experience, yet surprisingly, little research exists that

Jean Williams is with the Department of Psychology at the University of Arizona, Tucson, AZ 85721. E-mail: williams@u.arizona.edu. Laura Kenow is with the Dept. of Health, Human Performance and Athletics at Linfield College, McMinnville, OR. Gerald Jerome is with the Dept. of Kinesiology at the University of Illinois, Urbana-Champaign, IL. Tracie Rogers is with the Dept. of Kinesiology at Arizona State University, Tempe. Tessa Sartain and Greg Darland were students in the Dept. of Psychology at the University of Arizona, Tucson. 
identifies optimal coaching behaviors and factors that influence the effectiveness of particular behaviors. Although most coaches try to behave in ways that they feel will foster the success and personal development of their athletes, Smith, Smoll, and Curtis (1978) found that coaches actually have little awareness of how frequently they behave in various ways, much less the effect these behaviors have on their athletes. Wandzilak, Ansorge, and Potter (1988) also determined that coaches have only partially correct recall of their coaching behaviors compared to actual, systematically recorded behaviors.

Smoll and Smith (1989) proposed a model of leadership behaviors in sport that provides a theoretical foundation for studying coaching behaviors and their effects. This cognitive-behavioral model (see Figure 1) specifies that the coach behaves in a certain way; the athletes perceive and recall these behaviors; and, based on this perception and recall, the athletes have an evaluative reaction to the coach's behavior (see solid arrows). In turn, situational factors and coach and athlete individual difference variables (see dashed arrows) determine the coach's actual behavior and the athlete's perception, recall, and evaluation of the behavior. Thus, the ultimate effectiveness of coaching behaviors depends upon the many complex interactions of these variables.

Whenever a good theoretical model exists, it often provides the impetus for future research, but only if there are assessment tools to test the model. To date, Smoll and Smith have tested their leadership behaviors model using the Coaching

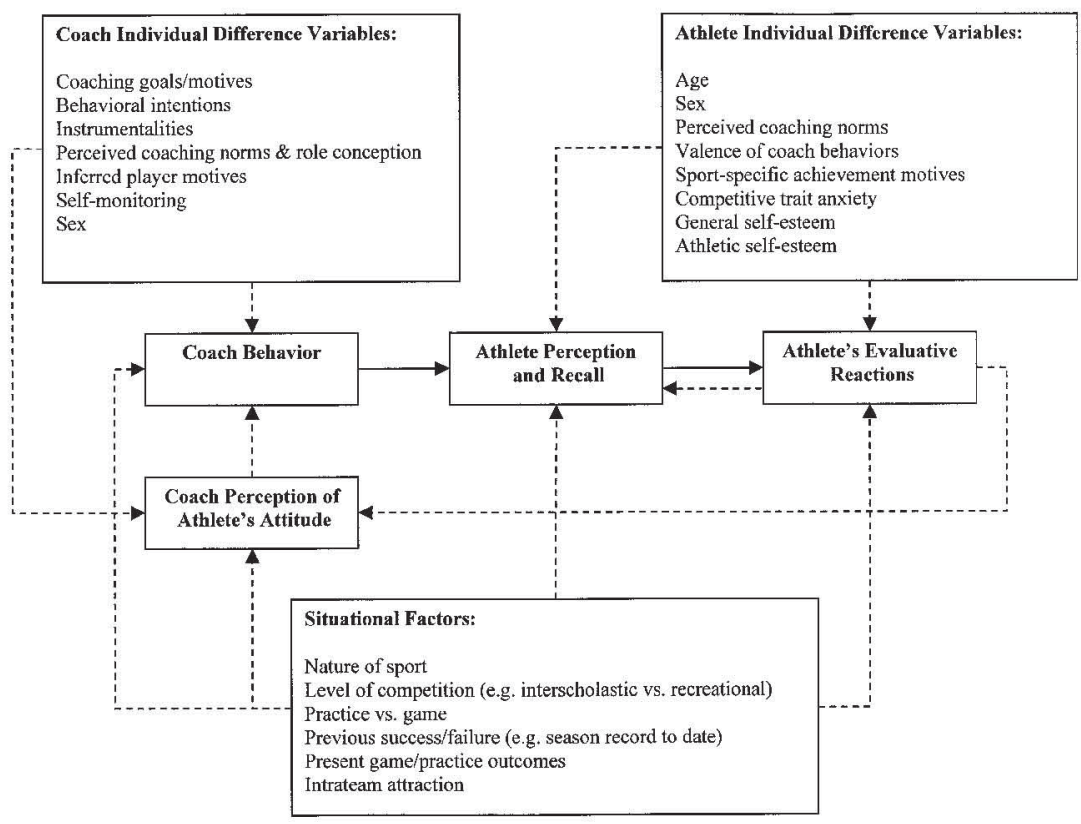

Figure 1 - Model of leadership behaviors in sport and hypothesized relationships among situational, cognitive, behavioral, and individual difference variables (adapted from Smoll \& Smith, 1989). 
Behavior Assessment System (CBAS; Smith, Smoll, \& Hunt, 1977), a procedure that involves raters observing practices and games in order to code 12 coaching behaviors (Smith \& Smoll, 1990; Smoll, Smith, Barnett, \& Everett, 1993). The CBAS includes categories such as reinforcement or nonreinforcement of good performance, mistake-contingent encouragement, technical instruction, general technical instruction or encouragement, punishment, punitive technical instruction, and general communication. The authors created it to measure coaching behaviors with youth sport participants, and others have successfully adapted it for use with college coaches (Solomon et al., 1996). The CBAS has proven effective at measuring actual coaching behaviors, but it does not assess athletes' evaluative reactions to the behaviors.

Integral to some aspects of the leadership model is the ability to quantify athletes' perceptions and evaluative reactions to their coach's behavior. Such measurement tools are scarce. Rushall and Wiznuk (1985) developed an objective, 36item Coach Evaluation Questionnaire that measures the coach across four areas: personal qualities, personal and professional relationships, organizational skills, and performance as a teacher and coach. One limitation of the questionnaire is that it focuses primarily on good coaching attributes and avoids any emphasis on negative features. Critical to testing athletes' evaluative reactions to coaching behaviors is the ability to determine both positive and negative behaviors and effects. Of particular interest is how athletes perceive their coach's behavior during competition and whether they evaluate the behavior as having a positive or negative effect on their performance and relevant psychological states. For example, do the coach's mannerisms and display of emotions during competition make the athlete feel tight and tense or help the athlete to relax and play better? Does the athlete think the coach has communicated clearly and constructively and in a way that builds confidence, or does the opposite occur?

The lack of any measurement vehicle for assessing athletes' perceptions and evaluative reactions to both positive and negative coaching behaviors led Kenow and Williams (1992) to develop a Coaching Behavior Questionnaire (CBQ). The CBQ consists of 28 items, including seven filler items designed to divert attention from the coach. The 21 coaching items came from the research of Percival (1971) and the coaching and sport psychology experience of the experimenters. Percival evaluated the responses of 382 athletes from 24 sports at all competitive levels. He found that athletes responded critically to areas such as coaches' mannerisms, emotionalism, verbal presentation, and tension level. After developing the CBQ, Kenow and Williams had six individuals with current or past coaching experience critique the items to determine clarity of wording and whether the items assessed behaviors important to coaching effectiveness.

Kenow and Williams (1992) administered the resulting CBQ to members of a female intercollegiate basketball team in order to test the prediction from Smoll and Smith's (1989) leadership model that game outcome and the athlete's competitive trait anxiety (CTA) influence athletes' perceptions and evaluation of their coach's game behaviors. They also tested whether the model should have state cognitive and somatic anxiety and self-confidence added to the list of athlete individual difference variables that affect perception and evaluation of coaching behaviors. Their first assessment had the players evaluate the behaviors that they perceived the coach would typically display under the hypothetical setting of competing against one of the top three teams that season in the athletic conference. 
Their second assessment examined whether these hypothetical findings would replicate to actual competition by administering the Competitive State Anxiety Inventory-2 (CSAI-2; Martens, Vealey, \& Burton, 1990) before and the CBQ immediately after a game against one of the top three teams in the conference. The second protocol thus assessed actual psychological states right before the game and the coach's specific game behaviors.

Both assessments provided support for Smoll and Smith's (1989) model and for adding some of the proposed athlete individual difference variables to the model. More specifically, Kenow and Williams (1992) found in the hypothetical setting that athletes who scored higher in CTA and cognitive state anxiety and lower in self-confidence evaluated the behaviors of the coach more negatively compared to players with the opposite profile. Except for self-confidence, similar results occurred in the actual competitive setting. The team won this competition in the final seconds with a free throw shot, which led Kenow and Williams to propose that the win may have increased the athletes' self-confidence levels such that the effect of low self-confidence did not occur. These researchers provided evidence for the potential value of using the CBQ to assess athletes' perceptions and evaluative reactions to their coach's behavior during competition, but they failed to address whether scoring and interpretation of the CBQ should occur with subscales rather than individual item scores and a total score.

Kenow and Williams (1999) later expanded upon their 1992 study by examining whether differences in coach-athlete compatibility should be added to the athlete individual difference variables proposed by Smoll and Smith (1989) to influence athletes perceptions and evaluative reactions to coaching behaviors. With few exceptions, sport psychologists have given little attention to the interaction between coach and athlete and how that interaction contributes to maximum athlete performance. Carron and Bennett (1977) suggested that in determining coachathlete compatibility, it is necessary to assess not only the coach's personality and behavior, but also the athlete's desire for such traits and behaviors in the coach. The Kenow and Williams' (1999) basketball results indicated that players who felt more compatible with their coach perceived fewer negative cognitive/attentional and somatic effects from their coach's game behavior compared to those players who felt less compatible with the coach. Higher compatibility also correlated with perceiving more supportive behavior from the coach and better communication and emotional composure.

Neither the research of Percival (1971) nor other research and theoretical models provide a clear conceptual foundation for specifying an a priori factor structure for the CBQ. In subsequent research with the CBQ, Kenow and Williams (1993) did conduct an exploratory factor analysis (EFA) to examine how to score the CBQ. Their findings identified five possible subscales, but too few participants prevented them from validating the identified factors with confirmatory factor analysis (CFA) and other analyses. One purpose of the present study was to reexamine the factor structure of the CBQ by administering it to a large enough pool of diverse participants to conduct both EFA and CFA analyses. Due to the lack of a clear conceptual foundation for the CBQ, we are adapting a commonly used strategy of splitting the data into two samples and performing an EFA on one sample and a CFA on the other sample. Research has shown that EFA is effective in specifying known models from sample data (Gerbing \& Hamilton, 1996), thus demonstrating the usefulness of EFA in model specification and subsequent theory 
development when used in conjunction with CFA (Fabrigar, Wegener, MacCallum, \& Strahan, 1999; Gerbing \& Hamilton, 1996). We are building on this common strategy by using CFA to compare models identified in an EFA to that of a single factor model.

Another shortcoming of the Kenow and Williams research $(1992,1993)$ was the homogenous samples (only women's intercollegiate basketball players), thus limiting the degree to which the findings can be generalized. The second purpose of the present research was to determine if the earlier Kenow and Williams' findings for athlete individual difference variables would replicate across a larger sample and to other sports. Multiple sports were examined because athletes from different sports vary in their preferences and perceptions of coach leadership behavior (Chelladurai, 1984) and because nature of the sport is included in Smoll and Smith's leadership model as one of the situational factors presumed to influence coaching behaviors and athletes' reactions to them.

\section{Methods}

\section{Participants}

A total of 484 college $(n=273)$ and high school $(n=211)$ athletes from basketball $(n=230)$, softball $(n=53)$, baseball $(n=93)$, and volleyball $(n=108)$ completed the questionnaires. The participants had a mean age of 17.7 years with males $(n=$ 252) and females $(n=232)$ represented similarly. The athletes were Caucasian $(54 \%)$, Mexican or Latino (30\%), Asian (5\%), American Indian (4\%), African American (2\%), or other (5\%). Participants had almost one full season or more playing experience under their current head coach. Schools and participants participated voluntarily and with procedures that assured anonymity.

\section{Instruments}

Coaching Behavior Measure. The Coaching Behavior Questionnaire (CBQ; Kenow \& Williams, 1992) assessed athletes' perceptions and evaluation of coaching behaviors. The CBQ consists of 28 items ( 21 actual items and 7 noncoaching fillers) with each responded to on a 4-point Likert scale of 1 (strongly disagree), 2 (disagree), 3 (agree), and 4 (strongly agree). Positively worded items (e.g., "Criticism from my coach is done in a constructive manner.") were reverse scored so that higher total scores reflected a more negative evaluation of the coach's game behaviors. The directions asked the athletes to assess coaching behaviors that typically occurred when they played against one of the top three teams in the conference that season. When necessary, minor wording variations were made to reflect the appropriate terminology for the sport (e.g., halftime vs. between innings).

Anxiety/Confidence Measures. The Sport Competition Anxiety Test (SCAT; Martens, 1977) assessed competitive trait anxiety (CTA). The Competitive State Anxiety Inventory-2 (CSAI-2; Martens et al., 1990) measured competitive state anxiety and self-confidence. The CSAI-2 assesses the intensity of perceived self-confidence and somatic and cognitive anxiety symptoms. The developers of both instruments report good psychometrics. Modified instructions for the CSAI2 directed participants to respond as if they were about to play one of the top three teams in the conference. 
Compatibility Measure. Participants were asked to rate how compatible they felt they were with their coach on a 9-point scale ranging from 1 (not very compatible) to 9 (highly compatible). Compatibility was defined as "the degree to which your (athlete's) goals, personality, and beliefs are consistent with your coach's goals, personality, and beliefs." This assessment was identical to that used by Kenow and Williams (1999), thus enabling a comparison with their results. They provided no psychometric data on the scale.

\section{Procedure}

In most cases, a trained research assistant not associated with the team administered the questionnaires. When this procedure was not possible, questionnaire packets and detailed instructions for testing the athletes were mailed to the coaches. To help ensure anonymity, the coaches left the room after passing out the packets and reading the testing instructions to the athletes. The athletes completed the questionnaires, sealed their responses in an envelope, signed their name across the seal, and placed the envelope into a large manila envelope that was returned to the investigators. Testing took place prior to a practice session during the last third of the season. In most cases, no games occurred within two days of the testing session in order to lessen any potential response distortion.

\section{Results}

\section{Descriptive Statistics}

Table 1 contains the 21 coaching items of the CBQ as well as item means, standard deviations, skewness, and kurtosis. The seven filler items were not included in the analyses. The data appear to be positively skewed with a mean skewness of .39, although the kurtosis appears to be more normally distributed with a mean of - 22 . It is recognized that this data may not be multivariate normal as indicated by a Mardia coefficient of $84.51(p<.05)$.

The entire sample $(N=484)$ was randomly divided into two, approximately equal data sets. Sample $1(n=240)$ provided the data for an EFA and sample $2(n=$ 244) provided the data for a CFA. The results of a MANOVA indicated no significant differences $(p<.05)$ for age, gender, ethnicity, sport, or competitive level between the two samples.

\section{Exploratory Factor Analysis}

We used Statistical Package for Social Sciences (SPSS: version 9.0) to conduct an EFA with generalized least squares estimation and direct oblimin rotation (delta $=$ 0 ). When reporting the items for each of the factors, we only included items with factor coefficient loadings at or above .40. Although McDonald (1999) suggests that it is commonly accepted to consider an item as salient if its factor loading is at least .30, we adopted a more rigorous standard based upon Hair, Anderson, Tatham, and Black's (1995) suggestion that in a sample size of 200 using loadings of at least .40 will provide more statistical power $($ power $=.80)$ than a loading of at least .30 (power < .80). Also, in an attempt to identify simple structures (Thurstone, 1947), we excluded items that met the .40 cutoff on more than one factor.

Four eigenvalues of 1.0 or greater were obtained from the extraction $\left(\lambda_{1}=\right.$ $\left.6.3, \lambda_{2}=1.97, \lambda_{3}=1.38, \lambda_{4}=1.00\right)$, accounting for $31.51 \%, 9.85 \%, 6.88 \%$, and 


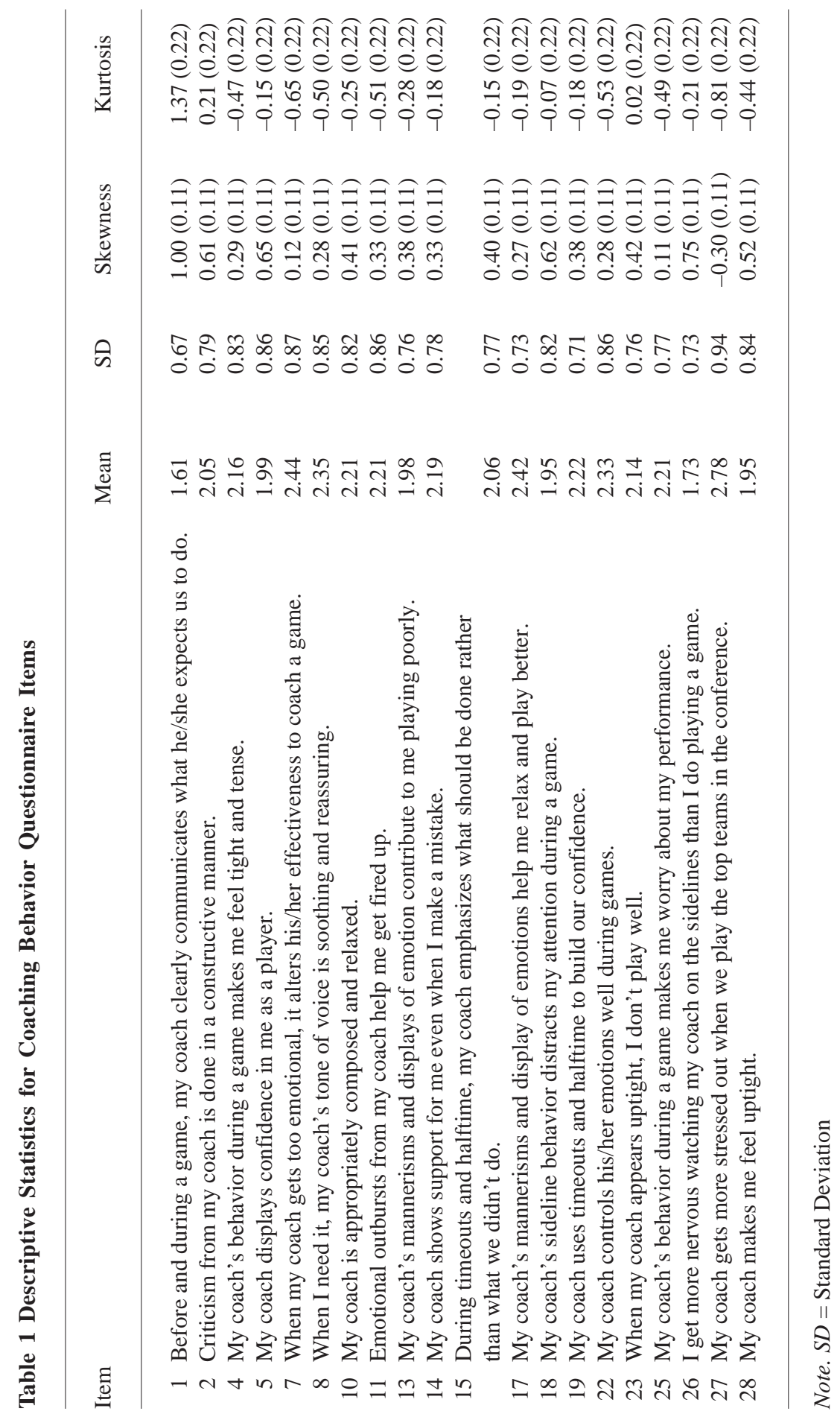


$5.05 \%$ of the variance. The authors identified both the 2-factor and 3-factor solutions as conceptually feasible structures. The identified 4-factor model had a factor measured by only one item with a loading above .40 and was consequently dropped from the analyses. The 2-factor solution (see Table 2) can be viewed as having a negative activation factor (Factor 2; items 4, 13, 18, 23, 25, 26, 28) and a supportiveness/emotional composure factor (Factor 1; items 2, 8, 10, 14, 15, 17 , 19, 22). The 3-factor solution retains a similar negative activation factor (Factor 2; items 4, 13, 18, 23, 25, 26), a communication factor (Factor 3; items 1, 2, 5), and an emotional composure factor (Factor 1; items 10, 14, 22).

\section{Confirmatory Factor Analysis}

Sample 2 was used for a CFA conducted with AMOS (Arbuckle, 1977) comparing the fit of the models identified in the EFA with a more parsimonious, single factor model. The covariance matrix for Sample 2 can be found in Table 3. Maximum likelihood estimation (ML) was used in the CFA even after a review of Mardia's coefficient indicated that this data may not be multivariate normal. Although ML is based on an assumption of multivariate normality, it has been shown to provide better estimation than methods that do not assume multivariate normality such as Browne's (1982) asymptotically distribution-free (ADF) estimation (Tanaka, 1984). McDonald and Ho (in press) also support the use of ML in this situation, reporting that ML is fairly robust with nonmultivariate normal data and that ADF requires samples far larger than the sample in the current study. Muthen and Kaplan (1992) demonstrated that the use of ML with nonnormal data can result in inflated chisquare and underestimated standard errors. Consequently multiple fit indices were used to determine model fit.

Three different models were tested: a 1-factor model and both a 2- and 3factor model based on the 2-factor and 3-factor EFA solutions. The factors within the models were allowed to correlate. The models were compared using multiple fit indices including an absolute fit index, Root Mean Square Error of Approximation (RMSEA, Browne \& Cudek, 1993), and two relative fit indices: the TuckerLewis Index (TLI; Tucker \& Lewis, 1973) and the Unbiased Relative Fit Index (URFI; McDonald \& Marsh, 1990), which is also identified as the Comparative Fit Index (CFI; Bentler, 1990). These indices were selected based on positive reviews by Browne and Cudek (1993) and McDonald and Marsh (1990). RMSEA is an approximation of the average residual covariance for a population with a RMSEA of .05 generally indicating a good fit (Browne \& Cudek, 1993). The RMSEA 90\% confidence interval (CI) will be used to determine closeness of fit with power of $.80(\alpha=.05)$. This is based on the recommendations of MacCallum, Browne, and Sugawara (1996), who provide a detailed explanation and rationale for power analysis in covariance structure modeling. The relative fit indices generally range from 0 to 1 with indices above .90 indicating a good fit. The TLI compares fit to a null model taking into account degrees of freedom; consequently, more parsimonious models have higher indices. The URFI provides an index similar to the TLI, yet the URFI is more robust with smaller samples and is less biased.

The 2-factor model provided the best overall fit (see Table 4) with a RMSEA approaching $.05(\mathrm{RMSEA}=.059)$ and relative fit indices above $.90(\mathrm{TLI}=.92$, URFI $=.93$ ), indicating a good fit. Since the lower bound of the RMSEA 90\% CI is below .05, the model is said to have a close fit (MacCallum, Browne, \& Sugawara, 1996). A test of close fit based on the CI indicates that this model has a sufficient 
Table 2 Pattern Matrix from Exploratory Factor Analysis

\begin{tabular}{|c|c|c|c|c|c|c|c|}
\hline \multirow[b]{3}{*}{ Item } & \multicolumn{3}{|c|}{ 2-factor } & \multicolumn{4}{|c|}{ 3-factor } \\
\hline & \multicolumn{2}{|c|}{ Pattern Matrix } & \multirow[t]{2}{*}{ Uniqueness } & \multicolumn{2}{|c|}{ Pattern Matrix } & \multicolumn{2}{|c|}{ Uniqueness } \\
\hline & F 1 & $\mathrm{~F} 2$ & & F 1 & F 2 & F 3 & \\
\hline 1 & .238 & .006 & .750 & -.055 & -.016 & .495 & .600 \\
\hline 2 & .579 & .147 & .539 & .341 & .115 & .422 & .432 \\
\hline 4 & .190 & .577 & .518 & .219 & .580 & .031 & .391 \\
\hline 5 & .335 & .278 & .596 & .010 & .185 & .611 & .439 \\
\hline 7 & .349 & .272 & .663 & .384 & .304 & -.170 & .576 \\
\hline 8 & .723 & .080 & .530 & .404 & -.119 & .531 & .40 \\
\hline 10 & .763 & .016 & .426 & .821 & .097 & -.065 & .273 \\
\hline 11 & .106 & .117 & .877 & -.058 & .070 & .283 & .808 \\
\hline 13 & .137 & .568 & .570 & -.019 & .513 & .301 & .451 \\
\hline 14 & .612 & .116 & .533 & .431 & .108 & .321 & .431 \\
\hline 15 & .477 & .135 & .683 & .341 & .130 & .246 & .627 \\
\hline 17 & .588 & .057 & .670 & .354 & -.076 & .384 & .584 \\
\hline 18 & .146 & .563 & .581 & .164 & .559 & .047 & .476 \\
\hline 19 & .569 & -.133 & .722 & .368 & -.141 & .322 & .641 \\
\hline 22 & .657 & .074 & .472 & .798 & .167 & -.189 & .306 \\
\hline 23 & -.260 & .604 & .732 & -.146 & .593 & -.114 & .627 \\
\hline 25 & .059 & .651 & .562 & -.061 & .629 & .083 & .45 \\
\hline 26 & .136 & .517 & .622 & .201 & .528 & -.033 & .531 \\
\hline 27 & .243 & .256 & .781 & .223 & .262 & .066 & .725 \\
\hline 28 & .079 & .765 & .433 & -.476 & .700 & .307 & .395 \\
\hline
\end{tabular}

Note. $\mathrm{F} 1$ = Factor 1, F 2 = Factor 2, F $3=$ Factor 3

sample size in comparison to its degrees of freedom to achieve power .80 with $\alpha$ set at .05 (MacCallum, Browne \& Sugawara, 1996). Each of the items had significant $(p<.001)$ loading (see Table 5) and the mean standardized loading was moderate $(M=.62$, $\min =.47, \max =.78)$. The factors had a moderate correlation $(r=$ $.60, p<.001)$ and acceptable reliability with the Cronbach alpha coefficients (Negative Activation $\alpha=0.82$, Supportiveness/Emotional Composure $\alpha=.83$ ) above the .70 level recommended by Nunnally (1978).

\section{Relationship Between CBQ Scores and Athlete Variables}

Correlational analyses were used to assess the relationship between the athletes' evaluation of coaching behaviors on the two CBQ factors and the athletes' selfreported competitive trait anxiety (CTA), cognitive and somatic state anxiety, state self-confidence, and coach-athlete compatibility (see Table 6). Except for coachathlete compatibility, correlational analyses were conducted on three data sets: intercollegiate basketball $(n=207)$, intercollegiate baseball/softball $(n=156)$, and 


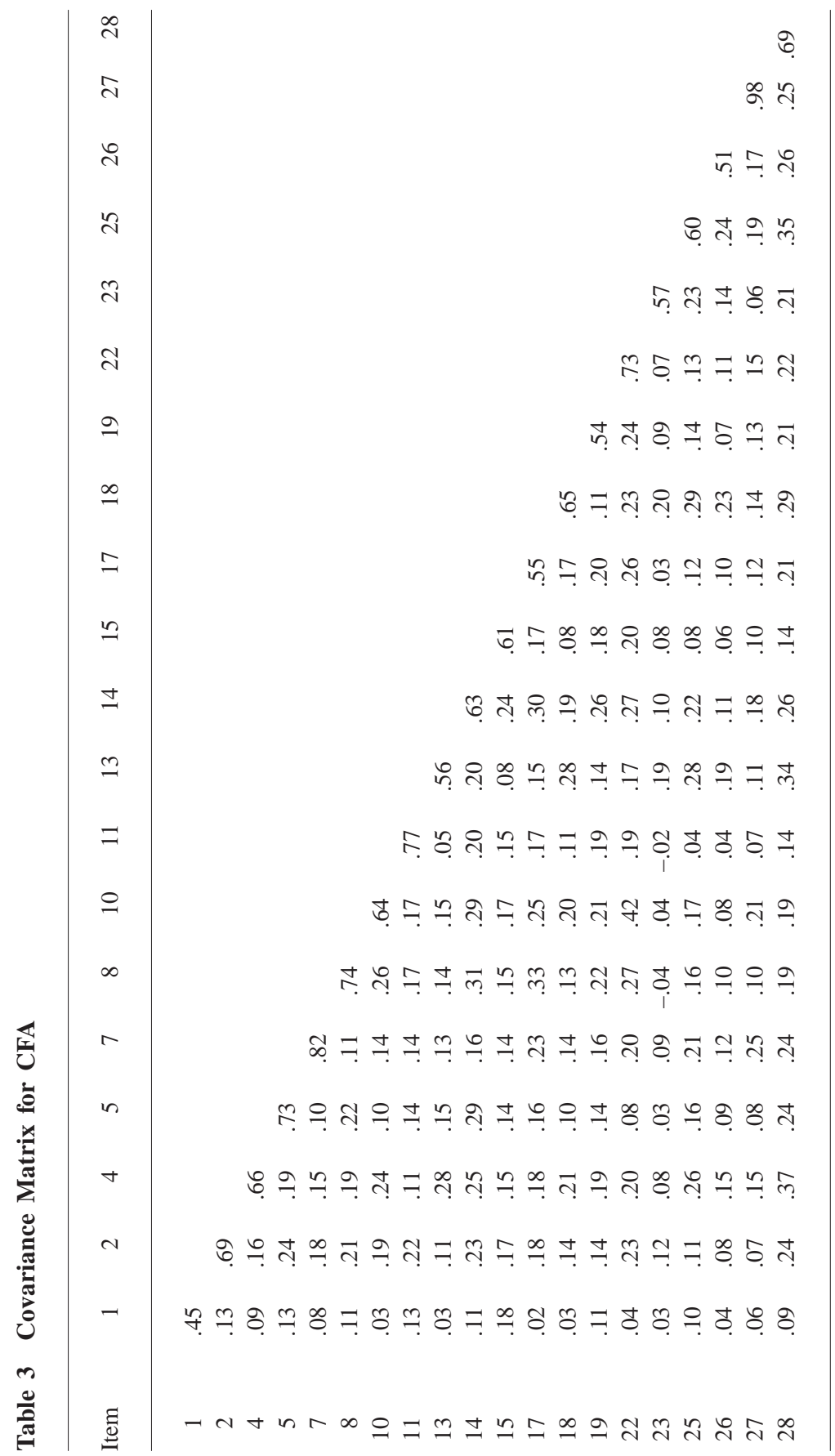


Table 4 Summary of Fit Statistics for Coaching Behavior Questionnaire Models

\begin{tabular}{|c|c|c|c|c|c|c|c|}
\hline \multirow[b]{2}{*}{ Model } & \multirow[b]{2}{*}{$x^{2}$} & \multirow[b]{2}{*}{$d f$} & \multirow[b]{2}{*}{ RMSEA } & \multicolumn{2}{|c|}{ RMSEA 90\% CI } & \multirow[b]{2}{*}{ TLI } & \multirow[b]{2}{*}{ URFI } \\
\hline & & & & $\begin{array}{l}\text { Lower } \\
\text { bound }\end{array}$ & $\begin{array}{l}\text { Upper } \\
\text { bound }\end{array}$ & & \\
\hline 1-factor & $528.53^{*}$ & 170 & 0.094 & 0.085 & 0.103 & 0.72 & 0.75 \\
\hline 2-factor & $164.28 *$ & 89 & 0.059 & 0.045 & 0.074 & 0.92 & 0.93 \\
\hline 3-factor & $111.22 *$ & 41 & 0.085 & 0.066 & 0.104 & 0.84 & 0.88 \\
\hline
\end{tabular}

$* p<.001$

high school volleyball $(n=108)$. Compatibility data was available on only one intercollegiate basketball sample $(n=68)$ and the high school volleyball sample.

Across all sports, athletes who reported higher trait anxiety and lower selfconfidence prior to competition were more likely to perceive that their coach engaged in behaviors during competition that would have a negative effect on them compared to athletes who were less anxious and more confident. The same negative activation perceptions occurred for athletes reporting higher cognitive (except for the volleyball players) and somatic (except for the basketball players) state anxiety and for basketball players that perceived less compatibility with their coach.

Across all sports in which there were data, players who reported lower selfconfidence and less coach-athlete compatibility perceived their coach as having shown fewer supportive behaviors and less emotional composure during the competition compared to athletes with the opposite profile. In addition, volleyball players with lower cognitive and somatic state anxiety perceived their coaches as less supportive and having less desirable emotional composure.

\section{Discussion}

The CBQ has been used in previous research, but the factor structure has never been adequately examined. The results of the current CFA support a 2-factor model for the CBQ. A conceptual examination of each of the items in the two factors, labeled negative activation and supportiveness/emotional composure, revealed a logical grouping of the individual items. In addition, the statistical results indicated acceptable internal consistency for the subscales. The lack of fit for the 1and 3-factor models, the good fit of the 2-factor model, and the moderate correlation between negative activation and supportiveness/emotion composure suggests that the CBQ measures two different aspects of coaching behavior. This finding does not imply that athletes' perceptions and evaluation of coaching behaviors are strictly two dimensional, only that the CBQ provides measurement of two different aspects of coaching behavior. Scoring the CBQ with these subscales is preferable to the individual items and total score used by Kenow and Williams (1992) and also their scoring with five subscales $(1993,1999)$. 


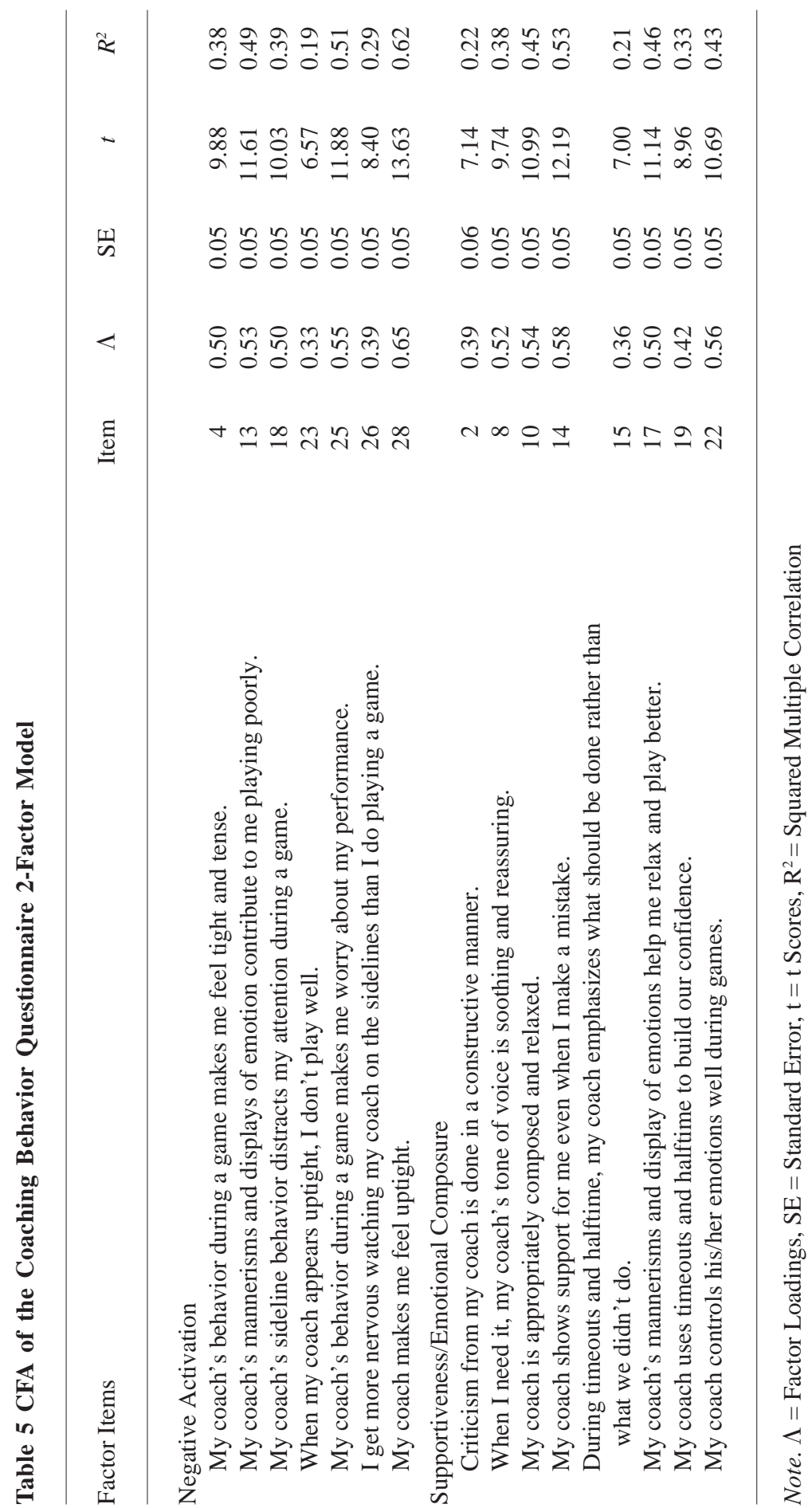


Table 6 Correlations between Coaching Behavior Questionnaire, Anxiety, SelfConfidence, and Compatibility

\begin{tabular}{llcc} 
& & \multicolumn{2}{c}{$\begin{array}{c}\text { Coaching Behavior } \\
\text { Questionnaire }\end{array}$} \\
\cline { 3 - 4 } Sport & & $\begin{array}{c}\text { Negative } \\
\text { Activation }\end{array}$ & Supp/EC \\
& & & \\
Basketball & Cognitive Anxiety & $.30^{* *}$ & .09 \\
& Somatic Anxiety & .12 & .08 \\
& Self Confidence & $-.20^{* *}$ & $-.14^{* *}$ \\
& Trait Anxiety & $.17^{*}$ & .10 \\
& Compatibility & $-.41^{* *}$ & $-.59^{* *}$ \\
Baseball/ Softball ${ }^{2}$ & $.28^{* *}$ & -.02 \\
& Cognitive Anxiety & $.18^{*}$ & .06 \\
& Somatic Anxiety & $-.23^{* *}$ & $-.17^{* *}$ \\
& Self Confidence & $.21^{*}$ & .02 \\
Volleyball & Trait Anxiety & .14 & $-.20^{*}$ \\
& Cognitive Anxiety & $.34^{* *}$ & $-.22^{*}$ \\
& Somatic Anxiety & $-.29^{* *}$ & $-.28^{* *}$ \\
& Self Confidence & $.28^{* *}$ & -.11 \\
& Trait Anxiety & -.17 & $-.36^{* *}$ \\
& Compatibility & & \\
\hline
\end{tabular}

Note. Supp/EC = Supportiveness/Emotional Control

${ }^{1}$ Compatibility data was only available for one intercollegiate basketball sample $(n=68)$.

${ }^{2}$ Compatibility data was not available for the baseball/softball sample.

$* p<.05$

$* * p<.001$

The psychometric findings on the CBQ and the correlations between the CBQ scores and the individual athlete variables support the viability of using the CBQ to assess facets of Smoll and Smith's (1989) sport leadership model that considers athletes' perceptions and evaluative reactions to their coach's behavior. The correlational analyses also provide support for the model's inclusion of competitive trait anxiety as one of the athlete individual difference variables (see Figure 1) that influence how athletes perceive and evaluate coaching behaviors. In addition, they support Kenow and Williams' $(1992,1999)$ proposal to add cognitive and somatic state anxiety, self-confidence, and compatibility with the coach to the list of athlete variables in the model. The overall findings lend credence to Smoll and Smith's claim that "the ultimate effects of coaching behaviors are mediated by the meaning that players attribute to them. In other words, cognitive and affective processes serve as filters between overt coaching behaviors and youngsters' attitudes toward their coach and their sport experience" (p. 1527).

The strongest relationship of athletes' individual difference variables to perception and evaluation of coaching behaviors occurred with the CBQ subscale that assessed negative activation. Athletes who reported higher competitive trait anxiety, 
more cognitive and somatic state anxiety, and less self-confidence were more likely to perceive that the coach's behavior during a game caused them to feel tense and uptight and had a negative influence on their cognitions, attention, and performance. The only exceptions were volleyball players on cognitive anxiety and basketball players on somatic anxiety.

According to trait anxiety theory, individuals with high anxiety are more likely to perceive stimuli as threatening, including objectively nondangerous stimuli (Martens et al., 1990; Spielberger, 1966). Evidence also indicates that situations that involve threat to self-esteem or potential failure are perceived as powerful sources of threat (Spielberger, 1972). The resulting insecurities of the high trait anxious athletes may have led them to overexaggerate perceived negative mannerisms and feedback in their coach's behavior prior to and during competition. Thus, coaching behaviors that appear neutral or constructively critical to moderate or low trait-anxious athletes may be interpreted negatively by the high-anxious athletes as a result of the self-doubt, worry, and elevated autonomic arousal already present.

If the higher trait-anxious and cognitive and somatic state-anxious athletes did interpret more coaching behaviors as threatening, then it is not surprising that these athletes would evaluate the coaching behaviors as having caused them more worry, distracted attention, elevated physiological arousal, and poorer performance compared to athletes whose self-report indicated lower anxiety levels. The preceding rationale also could explain the similar negative evaluation of coaching behaviors by athletes who lacked or had lower self-confidence. The failure to obtain similar somatic anxiety findings in the basketball players suggests perhaps a lower susceptibility to the negative effects of pregame somatic anxiety when athletes participate in a sport that requires more sustained aerobic activity compared to sports like baseball/softball and volleyball where a higher proportion of competition time is spent standing or sitting. This suggestion is based upon exercise research that has shown larger reductions in self-rated anxiety tend to occur when exercise is more sustained and of moderate intensity (O'Connor, Petruzzello, Kubitz, \& Robinson, 1995; Petruzzello, Landers, Hatfield, Kubitz, \& Salazar, 1991).

Across all sports, athletes scoring lower in self-confidence perceived less supportiveness and emotional composure from their coach. These athletes were more likely to evaluate their coaches as having failed to show support after mistakes, to offer criticism in a constructive manner, and to display positive mannerisms and emotions. They also were more likely to perceive that their coach failed to use a soothing and reassuring tone of voice, to emphasize what should be done, and to actively build athlete confidence. These results make intuitive sense in that athletes with low confidence would need more positive communication and supportive behaviors, and particularly so after having performed poorly. These athletes would, therefore, be more receptive to perceiving a lack of these coaching behaviors compared to athletes with the opposite psychological profile.

Whereas the correlations between self-confidence and the subscale supportiveness/emotional composure make intuitive sense, the significant anxiety correlations do not. That is, volleyball players with higher cognitive and somatic state anxiety perceived their coaches as more supportive and having better emotional composure. These ratings are in the opposite direction of what one would expect and also of the anxiety-negative activation correlations. Differences in anxiety levels did not influence the ratings of supportiveness/emotional composure by 
the basketball, baseball, and softball players. Future researchers will need to determine whether these results replicate and, if they do, what might explain the sport differences and the anxiety-supportiveness/emotional composure relationship with volleyball players. In addition, we recommend caution in placing too much emphasis on most of the self-confidence and anxiety results due to the below .30 values for most of the correlations, thus explaining less than $10 \%$ of the variance (Tabachnick \& Fidell, 1996).

Athlete differences in coach-athlete compatibility influenced three of the four ratings of coach behavior. All three correlations were higher (i.e., -.36, -.41, .59) than those found for anxiety and self-confidence. Basketball players who reported greater compatibility with their coach perceived and evaluated their coach's behavior as having less negative activation and more supportiveness and emotional composure, compared to players who reported lower coach/athlete compatibility. Similar ratings occurred for the volleyball players, but only on the subscale supportiveness/emotional composure. These findings are consistent with the work of Gordon (1988), although he assessed a different type of coach-athlete compatibility. He found high congruence scores between a coach's decision styles and those preferred and perceived by athletes predicted athlete perceptions of coaching effectiveness.

The present findings suggest that if the athlete's goals, personality, and beliefs are consistent with those of their coach, the interaction between the individuals will likely produce a positive interpersonal atmosphere. Conversely, if they have an incompatibility, then certain psychological needs for the athlete probably are not being met, and the athlete is more likely to negatively evaluate the coach's behavior. One shortcoming with trying to interpret the compatibility results is that assessment occurred with a single item and this item sampled an incredibly broad domain (goals, personality, beliefs). Future researchers should develop a multipleitem scale. Not only would it probably provide a more valid and reliable index of this domain, it would enable determination of the relative contributions of different facets of compatibility on relationship satisfaction and also the perception and evaluation of the effectiveness of various coaching behaviors.

In addition to the need for a more thorough examination of coach-athlete compatibility, future researchers should consider examining other athlete and coach individual difference variables that might influence coaching behaviors and athletes' perceptions and evaluative reactions to the behaviors. Besides the variables identified in Smoll and Smith's (1989) leadership model (see Figure 1), more recent coaching research suggests additional variables that hold promise. For example, Solomon (1999b) found that athletes' years of competitive experience and the coach's performance expectations for athletes influenced the athletes' evaluation of coach effectiveness. In related studies, Solomon and colleagues found that head and assistant coaches gave different feedback to athletes based upon their expectancies for the athletes' performance (Solomon et al., 1996) and the ethnicity of the coach and the athletes (Solomon, 1999a). Anshel and Straub (1991) found that high school and college football players perceived coaching behaviors more negatively when the coach failed to provide for individualized treatment of athletes.

Some of the preceding research raises interesting questions regarding the actual behavior of the coaches in the present study and how their behavior might have varied for different athletes. Unfortunately, none of the studies that used the 
CBQ determined whether the coach actually behaved differently toward athletes varying in psychological states and levels of compatibility. Our conjecture would be probably not. Even if they did, Shaver (1975) suggested that an individual's perception of another's behavior is more important than the behavior itself in determining one's feelings or actions toward the other person. Regardless, these results support Kenow and Williams' concern (1992) that coaches should not assume that given behaviors in specific situations have the same effect on all athletes. The results also emphasize the need for coaches to be aware of the anxiety and confidence levels of their individual athletes and of their degree of compatibility with individual athletes. Coaching behaviors that effectively inform, motivate, or lead the self-confident, low-anxious, and highly compatible athlete may have the opposite effect on the low-confident, anxious, and less compatible athlete. We would suggest that these latter athletes are less tolerant of negative mannerisms and criticism.

Sport psychology researchers, however, have found that coaches are not very accurate in predicting their athletes' psychological states (e.g., Hanson \& Gould, 1988; Krane, Finch, Gould, Eklund, \& Kelley, 1990). They also have found that coaches tend to perceive their own behaviors as more encouraging and supportive than either their actual practice and game behaviors would indicate or what their athletes' recall of coaching behaviors would suggest (e.g., Salminen, Luikkonen, \& Telama, 1992; Wandzilak et al., 1988). The challenge to the sport psychology community is to determine what influences the effectiveness of coaches in estimating their own coaching behaviors and their players' psychological states. The next step would entail identifying and testing interventions that would hopefully increase the accuracy of coach perceptions and that would help coaches modify their behaviors to maximize their effectiveness with different types of athletes.

A related approach might be to enhance coach and athlete interactions by testing the effectiveness of interventions designed to decrease athletes' anxiety levels and to increase their self-confidence. The premise would be that such modifications would hopefully lead to an improvement in athletes' perceptions and evaluative reactions to their coach's behavior. Evidence already exists for decreasing children's sport performance anxiety through social support and stress-reduction training for coaches (Smith, Smoll, \& Barnett, 1995). Smoll and Smith (1996) offer additional suggestions for intervention strategies to decrease competitive anxiety in athletes. A meta-analysis of sport psychology intervention studies identifies other techniques that researchers have used to modify athletes' anxiety and confidence levels (Meyers, Whelan, \& Murphy, 1996).

In conclusion, leader effectiveness resides in both the behaviors of the leader and the eyes of the beholder. Athletes' competitive trait anxiety, cognitive and somatic state anxiety, state self-confidence, and compatibility with the coach influence their perceptions and evaluation of coaching behaviors. The trait anxiety results support Smoll and Smith's (1989) model of leadership behaviors in sport and the results from the other variables indicate the merit for adding them to the list of athlete individual difference variables thought to influence perception and evaluative reactions to coaching behaviors. Further, the analysis of the CBQ indicates that it retains two factors across high school and intercollegiate athletes, males and females, and across multiple sports (i.e., basketball, softball, baseball, volleyball). However, sport psychology researchers should be wary of concluding that factor structures do not vary across different samples and cultures (Messick, 
1989; Pedhazur \& Schmelkin, 1991). Gauvin and Russell (1993) provide a relevant recommendation to replicate, whenever possible, the original validity evidence pertaining to measurement instruments before using the instrument in research situations. Continued CFA research should be conducted with the CBQ to increase the generalizability and validity of the identified model.

\section{References}

Anshel, M.H., \& Straub, W.F. (1991). Congruence between players' and coaches' perceptions of coaching behaviors. Applied Research in Coaching and Athletics Annual, 49-65.

Arbuckle, J.L. (1997). AMOS (version 3.61). Chicago: Small Waters Corporation.

Bentler, P.M. (1990). Comparative fit indices in structural models. Psychological Bulletin, 107, 238-246.

Browne, M.W. (1982). Covariance structures. In D.M. Hawkins (Ed.), Topics in applied multivariate analysis (pp. 72-141). Cambridge, MA: Cambridge University Press.

Browne, M.W., \& Cudek, R. (1993). Alternative ways of assessing model fit. In K.A. Bollen \& S.J. Long (Eds.), Testing structural equation models (pp. 136-162). Newbury Park, CA: Sage.

Carron, A.V., \& Bennett, B.B. (1977). Compatibility in the coach-athlete dyad. Research Quarterly, 48, 671-679.

Chelladurai, P. (1984). Discrepancy between preferences and perceptions of leadership behavior and satisfaction of athletes in varying sports. Journal of Sport Psychology, $\mathbf{6}$, 27-41.

Fabrigar, L.R., Wegener, D.T., MacCallum, R.C., \& Strahan, E.J. (1999). Evaluating the use of exploratory factor analysis in psychological research. Psychological Methods, 4, 272-299.

Gauvin, L., \& Russell, S.J. (1993). Sport-specific and culturally adapted measures in sport and exercise psychology research: Issues and strategies. In R.N. Singer, M. Murphey, \& L.K. Tennant (Eds.), Handbook of research on sport psychology (pp. 891-900). New York: Macmillan.

Gerbing, D.W., \& Hamilton, J.G. (1996). Viability of exploratory factor analysis as a precursor to confirmatory factor analysis. Structural Equation Modeling, 3, 62-72.

Gordon, S. (1988). Decision styles and coaching effectiveness in university soccer. Canadian Journal of Sport Science, 13(1), 56-65.

Hair, J., Anderson, R., Tatham, R., \& Black, W. (1995). Multivariate data analysis with readings (4th ed.). Upper Saddle, NJ: Prentice-Hall.

Hanson, T.W., \& Gould, D. (1988). Factors affecting the ability of coaches to estimate their athletes' trait and state anxiety levels. The Sport Psychologist, 2, 298-313.

Kenow, L.J., \& Williams, J.M. (1992). Relationship between anxiety, self-confidence, and the evaluation of coaching behaviors. The Sport Psychologist, 6, 344-357.

Kenow, L.J., \& Williams, J.M. (1993). Factor structure of the coaching behavior questionnaire and its relationship to anxiety and self-confidence. Journal of Sport and Exercise Psychology (Supplement), 15, S45.

Kenow, L.J., \& Williams, J.M. (1999). Coach-athlete compatibility and athlete's perception and evaluative reactions to coaching behaviors. Journal of Sport Behavior, 22, 251-259.

Krane, V., Finch, L., Gould, D., Eklund, R., \& Kelley, B. (September, 1990). Factors influencing coaches' ability to predict anxiety levels in their athletes. Symposium presented at the meeting of the Association for the Advancement of Applied Sport Psychology, San Antonio, Texas. 
MacCallum, R.C., Browne, M.W., \& Sugawara, H.M. (1996). Power analysis and determination of sample size for covariance structure modeling. Psychological Methods, $\mathbf{1}$, 130-149.

Martens, R. (1977). Sport competition anxiety test. Champaign, IL: Human Kinetics.

Martens, R., Vealey, R., \& Burton, D. (1990). Competitive anxiety in sport. Champaign, IL: Human Kinetics.

McDonald, R.P. (1999). Test theory: A unified treatment. Mahwah, NJ: Lawrence Erlbaum Associates.

McDonald, R.P. \& Ho, M. (in press). Principal and practice in reporting structural equation analyses. Psychological Methods.

McDonald, R.P. \& Marsh, H.W. (1990). Choosing a multivariate model: No centrality and goodness of fit. Psychological Bulletin, 107, 247-255.

Messick, S. (1989). Validity. In R.L. Linn (Ed.), Educational measurement (3 ${ }^{\text {rd }}$ ed., pp. 13103). New York: American Council on Education.

Meyers, A.W., Whelan, J.P., \& Murphy, S.M. (1996). Cognitive behavioral strategies in athletic performance enhancement. In M. Hersen, R.M. Eisler, \& P.M. Miller (Eds.), Progress in behavior modification (v. 30, pp. 137-164). Pacific Grove, CA: Brooks/ Cole.

Muthen, B. \& Kaplan, D. (1992). A comparison of some methodologies for the factor analysis of non-normal Likert variables: A note on the size of the model. British Journal of Mathematical \& Statistical Psychology, 45, 19-30.

Nunnally, J. (1978). Psychometric Theory ( $2^{\text {nd }}$ ed.). New York: McGraw-Hill.

O’Connor, P.J., Petruzzello, S.J., Kubitz, K.A., \& Robinson, T.L. (1995). Anxiety responses to maximal exercise testing. British Journal of Sports Medicine, 29, 97-102.

Pedhazur, E.J., \& Schmelkin, L.P. (1991). Measurement, design, and analysis: An integrated approach. Hillsdale, NJ: Erlbaum.

Percival, L. (1971). The coach from the athletes' viewpoint. In J.W. Taylor (Ed.), Proceedings, Symposium on the Art and Science of Coaching (pp. 285-325). Toronto: Fitness Institute.

Petruzzello, S.J., Landers, D.M., Hatfield, B.D., Kubitz, K.A., \& Salazar, W. (1991). A meta-analysis on the anxiety reducing effects of acute and chronic exercise: Outcomes and mechanisms. Sports Medicine, 11, 142-182.

Rushall, B.S., \& Wiznuk, K. (1985). Athletes' assessment of the coach: The Coach Evaluation Questionnaire. Canadian Journal of Applied Sport Sciences, 10, 157-161.

Salminen, S., Luikkonen, J., \& Telama, R. (1992). The differences in coaches' and athletes' perception of leader behaviour of Finnish coaches. In T. Williams, L. Almond, \& A. Sparkes (Eds.), Sport and physical activity: Moving towards excellence (pp. 517522). London: E. \& F.N. Spoon.

Shaver, K.J. (1975). An introduction to attribution processes. Cambridge, MA: Winthrop.

Smith, R.E., \& Smoll, F.L. (1990). Self-esteem and children's reactions to youth sport coaching behaviors: A field study of self-enhancement processes. Developmental Psychology, 26, 987-993.

Smith R.E., Smoll, F.L., \& Barnett, N.P. (1995). Reduction of children's sport performance anxiety through social support and stress-reduction training for coaches. Journal of Applied Developmental Psychology, 16, 125-142.

Smith, R.E., Smoll, F.L., \& Curtis, B. (1978). Coaching behaviors in Little League baseball. In F.L. Smoll \& R.E. Smith (Eds.), Psychological perspectives in youth sports (pp. 173-201). Washington, DC: Hemisphere.

Smith, R.E., Smoll, F.L., \& Hunt, E.B. (1977). A system for the behavioral assessment of athletic coaches. Research Quarterly, 48, 401-407. 
Smoll, F.L., \& Smith, R.E. (1989). Leadership behaviors in sport: A theoretical model and research paradigm. Journal of Applied Social Psychology, 19, 1522-1551.

Smoll, F.L., \& Smith, R.E. (1996). Competitive anxiety: Sources, consequences, and intervention strategies. In F.L. Smoll \& R.E. Smith (Eds.), Children and youth in sport: A biopsychosocial perspective (pp. 359-380). Dubuque, IA: Brown \& Benchmark.

Smoll, F.L., Smith R.E., Barnett, N.P., \& Everett, J.J. (1993). Enhancement of children's self-esteem through social support training for youth sport coaches. Journal of Applied Psychology, 78, 602-610.

Solomon, G.B. (1999a). Ethnic identity and coach feedback: Implications for effective coaching. Journal of Physical Education, Recreation and Dance, 70(2), 75-78.

Solomon, G.B. (1999b). Predictors of coach effectiveness in competitive sport: The role of actual and expected performance. International Sports Journal, 3, 25-36.

Solomon, G.B., Striegel, D.A., Eliot, J.F., Heon, S.N., Maas, J.L., \& Wayda, V.K. (1996). The self-fulfilling prophecy in college basketball: Implications for effective coaching. Journal of Applied Sport Psychology, 8, 44-59.

Spielberger, C.D. (1966). Theory and research on anxiety. In C.D. Spielberger (Ed.), Anxiety and behavior (pp. 3-20). New York: Academic Press.

Spielberger, C.D. (1972). Anxiety as an emotional state. In C.D. Spielberger (Ed.), Anxiety: Current trends in theory and research (Vol. 1, pp. 23-49). New York: Academic Press.

Tabachnick, B.G., \& Fidell, L.S. (1996). Using multivariate statistics (3 ${ }^{\text {rd }}$ ed.). New York: Harpers Collins.

Tanaka, J. S. (1984). "How big is big enough?”: Sample size and goodness of fit in structural equation models with latent variables. Child Development, 58, 134-146.

Thurstone, L.L. (1947). Multiple factor analysis. Chicago: University of Chicago Press.

Tucker, L.R., \& Lewis, C. (1973). A reliability coefficient for maximum likelihood factor analysis. Psychometrika, 38, 1-10.

Wandzilak, T., Ansorge, C.J., \& Potter, G. (1988). Comparison between selected practice and game behaviors of youth sport soccer coaches. Journal of Sport Behavior, 2, 7888 .

\section{Acknowledgments}

We would like to thank Roderick McDonald for his advice on the statistical analysis.

Manuscript submitted: May 21, 2001

Revision received: February 27, 2002 